\title{
Oral Microbial Isolates from Patients Attending the Dental Clinic, University College Hospital, Ibadan, Nigeria.
}

Authors:

Okoje, V.N. ${ }^{1}$

Akinmoladun, V.I. ${ }^{1}$,

Alonge, T.O. ${ }^{2}$

Authors' affiliations:

${ }^{1}$ Oral and Maxillofacial Surgery Department, College of Medicine/ UCH, Ibadan, Nigeria.

${ }^{2}$ Orthopedics and Trauma

Department, College of Medicine/ UCH, Ibadan, Nigeria.

\section{Corresponding} author: OkojeAdesomoju, V.N. Email address: vnokoje@gmail.com

\section{Authors' e-mail addresses:}

Dr. V.I. Akinmoladun:

viakinmoladun@yahoo.com

Dr. A.T. Adeyemi:

abigailadeyemi@yahoo.com

Prof. T.O. Alonge:

alonget2003@yahoo.com

Key words: Oral microbial isolates, Antibiotic therapy, Enterobacteria.

\section{ABSTRACT \\ Aim}

To evaluate microbial isolates from the buccal mucosa, carious teeth cavities and root tips of extracted carious teeth from patients attending the dental clinics of the University College Hospital, Ibadan, Nigeria. The isolates may guide the choice of preoperative antibiotics which hitherto has been based on "best guess".

\section{Materials and Method}

Consecutive consenting patients seen over a period of six months were included in the study.

Pre-tested questionnaires were administered for socio- demographic and oral hygiene information. This was followed by an intra-oral examination. Oral swab was performed using a sterile microscopic culturing swab stick which was run along the buccal and labial sulci of the jaws. The swab tips were cut into brain-heart infusion broth and the cultured micro-organisms plated out on blood agar. Microscopy, culture and sensitivity of the isolates were carried out using standard microbiological techniques.

Data was analyzed using SPSS version 19. Frequency tables were generated and measures of central tendency were calculated.

\section{Results}

One hundred and eighty-three patients were seen. The non- commensal microorganisms isolated from the oral sulcus were predominantly coliforms (Klebsiella species in $15.8 \%$, Escherichia coli in 13.70\%) with normal oral flora found in $12(6.6 \%)$ isolates. The carious cavities were also dominated by coliforms; Escherichia coli (20.6\%), Klebsiella species (12\%) and Proteus species $(8.62 \%)$ with $10.34 \%$ being the normal flora isolates. The isolates from the root tip of extracted carious teeth yielded mainly Escherichia coli (28.6\%) with no growth in over half of the samples.

High sensitivity of the isolates to quinolones and marked resistance to ampicillin and tetracycline were observed.

\section{Conclusion}

The isolation of invasive microorganisms from the oral cavity of our patients suggests the need for precautions that would reduce the oral microflora burden preoperatively. The antimicrobial antibiotic sensitivity pattern may guide the choice of prophylactic antibiotics in maxillofacial surgery. 


\section{Introduction}

The oral cavity is constantly bathed by saliva, which could be considered an environmental agent influencing the state of the oral health. Saliva has a buffering effect as a result of its high bicarbonate content and it augments the clearance of food particles in the mouth thereby reducing the population of the oral microbes. ${ }^{[1]}$ The saliva also contains antibodies and immunoglobullins; IgE, IgA and IgM with their inherent antibacterial activities. In addition it also contains cyanates, a lysozyme-like substance and other theoretically antibacterial substance. ${ }^{[1,2]}$

The composition of the oral microflora is highly complex and variable and to date at least 300 different species are known to be associated with the oral cavity and it is suggested that only half of them can be cultured. ${ }^{[3]}$ The resident or normal bacterial flora in the oral cavity in the developed and the developing world may differ considering the variety in environmental conditions, dietary habits, contaminants and immune status. ${ }^{[3]}$

The mucous membranes of the mouth are often sterile at birth but may be contaminated by passage through the birth canal within 4 12 hours. After birth, Streptococcus viridians become established as the most prominent member of the resident flora in the oral cavity and remain so for life. ${ }^{[2]}$ It is thought that these organisms (Streptococcus viridians) probably originated in the respiratory tracts of the mother and birth attendants.

Early in life (before teeth erupts) aerobic and anaerobic Staphylococcus, gram negative diplococcus (Neisseriae, Braxell catarrahalis), Diptheroids and occasional Lactobacilli are added to the oral microbial flora. $[4,5]$
However, when teeth begin to erupt, anaerobic spirochete such as Prevotella species, especially Prevotella melaninogenica, Fusobacterium species, Rothia species and Capnocytophage species establish themselves along with some anaerobic Vibros and Lactobacilli in the oral cavity. ${ }^{[5]}$ Along with this bacteria load, Actinomyces species are normally present in tonsillae tissue and gingivae in adults. Various protozoan and yeasts may also be present. ${ }^{[5]}$ In effect the mouth supports a wide variety of microorganisms including bacteria, yeasts, viruses and occasional protozoan, with bacteria being the predominant resident microflora. ${ }^{[5]}$

The mouth is therefore colonized by a characteristic commensal microflora, also referred to as normal flora that remains relatively stable as a result of a dynamic balance between inter bacterial and host bacterial interactions. These commensal oral flora together with other oral defense mechanisms play an important role in protecting the oral cavity from infection by exogenous organisms. [6]

The composition of the microflora of the mouth is highly complex and varies considerably from site to site and at different times because of the potential habitats for attachment in the oral cavity which include the non-shedding hard tooth surfaces and the soft, constantly replaced epithelia surfaces. ${ }^{[7]}$ At these sites in the oral cavity, there are variations in anaerobiosis, availability of nutrients, exposure to salivary secretions or gingival crevicular fluids and masticatory forces, all of which contribute to the variation in the types of microflora. ${ }^{[8]}$

Pattern of hand hygiene are developed and established in early life. For children with inadequate and poor toilet hygiene, enteric bacteria can pose a potential threat and danger 
by penetrating the body via the mouth as a result of nail-biting; so they can lead to various infections in the oral cavity. The need to provide proper hygiene instructions as a preventive measure was advocated. ${ }^{[9,10]}$

Therefore, an alteration in the delicate balance between the resident commensal or normal oral flora and the host, predispose to endogenous oral infection. The factors that predispose to oral infection include physiological factors such as pregnancy, trauma (local or general), malnutrition, immunosuppression, antimicrobial therapy, chemotherapy, oral malignancies, salivary flow dysfunction, dehydration and loss of masticatory muscle function. ${ }^{[11]}$

\section{Aim}

The aim of this study was to evaluate the microbial isolates in the buccal mucosa of the oral cavity, carious teeth cavities and root tips of extracted carious teeth from patients attending the dental clinic at the University College Hospital (UCH), Ibadan, Nigeria, with the intent of mapping out the characteristic commensal microbial isolates and assessing the appropriate antibiotic therapy in anticipation of dental (oral) infections.

\section{Materials and Methods}

Consecutive patients presenting at the oral diagnosis and oral surgery clinics of the University College Hospital (UCH), Ibadan over a period of six months were entered into the study. A self-administered questionnaire was completed by the patients after informed consent was obtained and swabs of the buccal mucosa, carious tooth cavities (where present) and the tips of roots of the extracted carious tooth were taken. Oral swab was performed using a sterile microscopic culturing swab stick (FL Medical Swab, Plastic stick. w/,
Rayon tip; 12 x 150 in polypropylene test tubes) which was run along the entire buccal and labial sulci of both the upper and lower jaws. Swabs of carious cavities (where present) and swabs from root tips of extracted carious teeth were obtained using sterile swab sticks. The swab tips were cut into brain - heart infusion broth and then cultured on chocolate, blood and McConkey agars in duplicates. One set was incubated aerobically at $37^{\circ} \mathrm{c}$ while the other set was incubated anaerobically in an anaerobic gas pack system (Oxoid HP0011A).

Isolates were identified by the API $20 \mathrm{~A}$ and microbacteria identification kits for anaerobes and aerobes respectively. Antimicrobial susceptibility was performed on confirmed pathogens by the Kirby- Bauer disk diffusion method.

Data were entered into a computer spread sheet and analysed using SPSS version 19. Frequency tables were generated and measures of central tendency calculated.

\section{Results}

One hundred and eighty-three consecutive patients were seen during the study period. There were 104 (56.8\%) females and 70 $(38.3 \%)$ and in $9(4.9 \%)$ cases, the sex was not indicated. Among the respondents, 50 (27.3\%) were students, $18(9.8 \%)$ were traders, $6(3.3 \%)$ were housewives respectively and 4 (2.2\%) lecturers. The others were priests, youth corper, business men and civil servants, caterer, farmers and researcher. Forty-five (45) of the respondents did not indicate their profession.

Fifty-three $(29.0 \%)$ of the respondents claim to brush their teeth twice daily (morning and night), 29 (15.8) brushed their teeth only in the morning, while $2(1.5 \%)$ used chewing stick to clean their teeth.

Twenty-nine patients $(15.8 \%)$ had previous tooth extraction, $46(25.1 \%)$ had other forms of 
dental procedures including scaling and polishing and surgical reconstructive procedures while $11(6.0 \%)$ were visiting the dentist for the first time.

Buccal mucosa swabs revealed normal flora, (Streptococcus albus) isolates in $12(6.6 \%)$ cases. Non-commensal micro-organisms were also isolated from the buccal mucosa and these included Klebsella species in $31(15.8 \%)$ cases, Escherichia coli in $23(12.6 \%)$ and Staphlococcus aureus in $13(7.0 \%)$ cases. Proteus species was isolated in $10(4.37 \%)$ and Brahamma catarrhalis in $7(3.82 \%)$ cases (Table 1)

Table 1: Oral microbial isolates from all patients

\begin{tabular}{|l|l|l|l|l|l|l|}
\hline $\begin{array}{l}\text { Microbial isolates from all } \\
\text { patients. }\end{array}$ & \multicolumn{3}{l}{ Buccal Sulcus } & \multicolumn{2}{l}{ Carious Cavities } & \multicolumn{2}{l|}{ Root Tips } \\
\hline Klebsiella Species & 31 & $16.9 \%$ & 7 & $12.1 \%$ & - & - \\
& & & & & & \\
\hline E. coli & 23 & $12.6 \%$ & 12 & $20.8 \%$ & 8 & $28.6 \%$ \\
\hline Normal flora & 12 & $6.5 \%$ & 6 & $10.4 \%$ & - & - \\
\hline Staph. aureus & 13 & $7.1 \%$ & 6 & $10.4 \%$ & - & - \\
\hline Beta Haemolytic Strep. & 10 & $5.5 \%$ & - & - & - & - \\
\hline Aerobic spore bearers (ASB) & 9 & $4.9 \%$ & 2 & $3.5 \%$ & 5 & $17.9 \%$ \\
\hline Proteus & 10 & $5.5 \%$ & 5 & $8.6 \%$ & - & - \\
\hline Brahamalis catarrhalis & 7 & $3.8 \%$ & 6 & $10.4 \%$ & - & - \\
\hline Pseudomonas & 8 & $4.2 \%$ & 1 & $1.7 \%$ & - & - \\
\hline Strep Pneumoniae & 4 & $2.1 \%$ & 4 & $6.9 \%$ & - & - \\
\hline Micrococcus serreti & 1 & $0.5 \%$ & - & - & - & - \\
\hline Anaerobic coliforms & 1 & $0.5 \%$ & - & - & - & - \\
\hline Non hemolytic Strep & 2 & $1.1 \%$ & - & - & - & - \\
\hline H. Influenzae & 1 & $0.5 \%$ & - & - & - & - \\
\hline Klebsiela species & 1 & $0.5 \%$ & - & - & - & - \\
\hline No growth & 28 & $15.3 \%$ & 9 & $15.5 \%$ & 15 & $53.6 \%$ \\
\hline Nil & 22 & $12.0 \%$ & - & - & - & - \\
\hline & & & & & & \\
\hline TOTAL & $\mathbf{1 8 3}$ & & $\mathbf{5 8}$ & & $\mathbf{2 8}$ & \\
\hline
\end{tabular}

In all the 58 carious teeth cavities that were swabbed, Escherichia coli was isolated in 12 (20.6\%) cases, Proteus species in 5 (8.62\%), Klebsiella species in 7 (12.0\%), Staphylococcus aureus in 6 (10.3\%), Pseudomonas in 1 (1.72\%), Streptococcus pneumoniae in 4 (6.89\%), Normal flora in 6 $(10.34 \%)$ while $9(15.5 \%)$ of the swabs yielded no growth (Table 1).
Twenty-eight root tips were swabbed immediately the teeth were extracted and the culture yielded Escherichia coli in 8 (28.6\%), Brahamma catarrhalis in $5(17.9 \%)$ and the remaining 15 (53.6\%) swabs yielded no growth.

Fifty of the patients (27.3\%) were on antibiotics within 2 weeks prior to the study. The combination of Amoxyl and Flagyl was the prescribed antibiotics in 11 (4.45\%), Amoxyl alone in $10(5.5 \%)$ cases, while $29(15.85 \%)$ of 
the patients used various combinations of other types of antibiotics.

The microbial isolates in those patients on antibiotics are shown in (Table 2) reflecting the predominance of Escherichia coli and Kleibsella species in the $8(17.4 \%)$ buccal swabs respectively and Escherichia coli in 4 (19\%) carious cavity swabs.

Table 2: Patients on antibiotics

\begin{tabular}{|l|l|l|l|l|l|l|l|}
\hline Organisms isolated & \multicolumn{2}{l|}{ Buccal sulcus } & \multicolumn{2}{l|}{ Carious cavities } & \multicolumn{2}{l|}{ Root tips } & Total \\
\hline $\begin{array}{l}\text { Brahamalis } \\
\text { catarrhalis }\end{array}$ & $\mathbf{7}$ & $\mathbf{1 5 . 2 \%}$ & $\mathbf{2}$ & $\mathbf{9 . 5 \%}$ & $\mathbf{6}$ & $\mathbf{6 6 . 7 \%}$ & $\mathbf{1 5 ( 1 9 . 7 \% )}$ \\
\hline E. coli & $\mathbf{8}$ & $\mathbf{1 7 . 4 \%}$ & $\mathbf{4}$ & $\mathbf{1 9 . 0 \%}$ & - & - & $\mathbf{1 2 ( 1 5 . 8 \% )}$ \\
\hline Kleb. Species & $\mathbf{8}$ & $\mathbf{1 7 . 4 \%}$ & $\mathbf{1}$ & $\mathbf{4 . 8 \%}$ & - & - & $\mathbf{9 ( 1 1 . 8 \% )}$ \\
\hline Strep aureus & $\mathbf{3}$ & $\mathbf{6 . 5 \%}$ & $\mathbf{1}$ & $\mathbf{4 . 8 \%}$ & $\mathbf{2}$ & $\mathbf{2 2 . 2 \%}$ & $\mathbf{6 ( 7 . 9 \% )}$ \\
\hline Proteus species & $\mathbf{2}$ & $\mathbf{4 . 4 \%}$ & $\mathbf{3}$ & $\mathbf{1 4 . 3 \%}$ & - & - & $\mathbf{5 ( 6 . 6 \% )}$ \\
\hline $\begin{array}{l}\text { Non haemolytics } \\
\text { Strep. }\end{array}$ & $\mathbf{3}$ & $\mathbf{6 . 5 \%}$ & $\mathbf{1}$ & $\mathbf{4 . 8 \%}$ & - & - & $\mathbf{4 ( 5 . 3 \% )}$ \\
\hline $\begin{array}{l}\text { Beta haemolytic } \\
\text { Strep. }\end{array}$ & $\mathbf{1}$ & $\mathbf{2 . 2 \%}$ & - & - & - & - & $\mathbf{1 ( 1 . 3 \% )}$ \\
\hline Pseudomons species & $\mathbf{3}$ & $\mathbf{6 . 5 \%}$ & $\mathbf{1}$ & $\mathbf{4 . 8 \%}$ & - & - & $\mathbf{4 ( 5 . 3 \% )}$ \\
\hline Strep peumoniae & $\mathbf{2}$ & $\mathbf{4 . 4 \%}$ & $\mathbf{2}$ & $\mathbf{9 . 4 \%}$ & $\mathbf{1}$ & $\mathbf{1 1 . 1 \%}$ & $\mathbf{5 ( 6 . 6 \% )}$ \\
\hline H. influenzae & $\mathbf{1}$ & $\mathbf{2 . 2 \%}$ & - & - & - & - & $\mathbf{1 ( 1 . 3 \% )}$ \\
\hline Normal flora & $\mathbf{4}$ & $\mathbf{8 . 7 \%}$ & $\mathbf{3}$ & $\mathbf{1 4 . 3 \%}$ & - & - & $\mathbf{7 ( 9 . 2 \% )}$ \\
\hline No growth & $\mathbf{4}$ & $\mathbf{8 . 7 \%}$ & $\mathbf{3}$ & $\mathbf{1 4 . 3 \%}$ & - & - & $\mathbf{7 ( 9 . 2 \% )}$ \\
\hline TOTAL & $\mathbf{4 6}$ & & $\mathbf{2 1}$ & & $\mathbf{9}$ & & $\mathbf{7 6}$ \\
\hline
\end{tabular}

Table 3 shows the antibiotic sensitivity pattern for the commensal isolates from the buccal cavity, carious cavities and root tips. Higher sensitivity to Quinolones (Ciprotab and Sparflotab) and greater resistance to Ampicillin and tetracycline were observed.

Table 3: Oral microbial isolates/ antibiotic sensitivity pattern

\begin{tabular}{|l|l|l|l|l|l|}
\hline $\begin{array}{l}\text { Microbial } \\
\text { isolates }\end{array}$ & $\begin{array}{l}\text { Ampicillin/ } \\
\text { Tetracycline }\end{array}$ & $\begin{array}{l}\text { Augmentin/ } \\
\text { Cephalexin }\end{array}$ & $\begin{array}{l}\text { Cefuroxime/ } \\
\text { Ceftazidime }\end{array}$ & \multicolumn{2}{|l|}{$\begin{array}{l}\text { Quinolones } \\
\text { Ciprotab/Sparflotab }\end{array}$} \\
\hline BS Sensitivity & $10(43.5 \%)$ & $15(65.5 \%)$ & $20(87.0 \%)$ & $20(87.0 \%)$ & $23(100 \%)$ \\
\hline BS Resistance & $13(56.5 \%)$ & $8(34.8 \%)$ & $3(13.0 \%)$ & $3(13.0 \%)$ & 0 \\
\hline CC Sensitivity & $2(16.7 \%)$ & $6(50.0 \%)$ & $10(83.3 \%)$ & $11(91.7 \%)$ & $12(100 \%)$ \\
\hline CC Resistance & $10(83.3 \%)$ & $6(50.0 \%)$ & $2(16.7 \%)$ & $1(8.3 \%)$ & 0 \\
\hline RT Sensitivity & $1(12.5 \%)$ & $2(25.0 \%)$ & $6(75.0 \%)$ & $8(100 \%)$ & $8(100 \%)$ \\
\hline RT Resistance & $7(87.5 \%)$ & $6(75.0 \%)$ & $2(25.0 \%)$ & 0 & 0 \\
\hline
\end{tabular}

\section{Key: BS - Buccal Sulcus \\ CC - Carious Cavities \\ RT - Root Tips}




\section{Discussion}

The mucous membrane of the mouth is sterile at birth but may be contaminated by passage of the baby through the birth canal. However, over time, the mouth becomes colonized by various organisms and to date, almost 300 micro-organisms have been documented as non-commensal microorganisms in the mouth. The predominant normal microflora includes Streptococcus viridians and Lactobacillus species. ${ }^{[12]}$

The oral cavity of healthy individual contains hundreds of different bacterial, viral and fungal species. Many of these can associate to form biofilms. They can become pathogenic as a result of changes in the oral environment or other triggers including an individual's personal hygiene. Their presence, therefore contribute to both health and diseases. ${ }^{[13]}$ Since disease states caused by diverse number of various microbial communities have been identified, microbial genomes have been paid a lot of attention in the era of personalized medicine. ${ }^{[14]}$

The isolation of coliforms in the buccal mucosa, carious teeth cavities and the root tips (following extraction of non-salvageable carious teeth) would suggest that the microbes in the buccal mucosa may be responsible for the root tip infection following propagation from the carious cavities.

In a healthy individual, the normal oral microbial ecosystem is remarkably stable despite its complexity but many endogenous factors may affect the composition and metabolic activity of the oral microflora.$^{[15]}$ The isolation of Pseudomonas aeruginosa from the oral cavity may be a pointer to the fact that some of these patients have had previous dental treatment and they could have acquired them as nosocomial infections.
Pseudomonas aerugenosa has been recognized as a pathogen of hospital patients in modern era of intensive treatment and antibiotic administration. ${ }^{[16,17]}$ Its ability to grow in most condition with simple nutrients and its comparative resistance to antibiotic and disinfectants has allowed it to become established and colonize the mucous membrane and skin of patients. ${ }^{[18]}$

The periodontal pockets in the gingival are particularly rich sources of organisms including anaerobes that are rarely encountered elsewhere. When implanted in another site, attention is drawn to them, for example Rothia dentocariosa and Capnocytophaga Species have been known to cause infective endocarditis and bacteremia in granulopenic host respectively. [19]

Proteus Species which are enterobacteria, frequently cause endogenous infections. It is present in rotten meat and sewage faeces, garden soil and vegetables. ${ }^{[20]}$ Proteus infection is very difficult to treat with a mortality of 18 $88 \%$ depending on the severity of the underlying disease; in addition, individual species differ in resistance to antibiotics. They may cause osteomyelitis of the jaws and are also linked to rheumatoid arthritis. ${ }^{[21]}$

A ready transmission of these emerging organisms has demonstrated the need to contain certain infections. ${ }^{[22]}$ Staphylococcus aureus is said to be carried by many normal people while streptococci is readily shed from the upper respiratory tract by coughing, sneezing and singing while Staphylococcus is shed in the skin squames during physical activity. ${ }^{[23,24]}$

The most important microorganisms spread by hand contact are Staphlococcus aureus and gram- negative bacilli such as Klebsiella and 
Serratia species ${ }^{[25]}$. Escherichia coli and Klebsiella are the most frequently encountered bacteria in hospital acquired infections ${ }^{[26]}$. Klebsiella is said to be carried by faecal route and transmitted by the hands, therefore poor general hygiene and specifically poor oral habits and deficiency in hand washing of carriers is suspected ${ }^{[27]}$.

Poeta et al., (2009) did not recover Enterococci or Escherichia coli from healthy volunteers, whereas 10 isolates were obtained from $19.5 \%$ of patients with fixed appliances. [28] However, Hable et al. studied 490 Minnesota children and found $4.7 \%$ prevalence of Enterobacteriaceae. ${ }^{[29]}$

Chang and Foltz (1960) in their study on 254 adult college students isolated coliform bacteria from oral cavity of $22(8.6 \%)$ adults, of these; three were identified as Escherichia coli ${ }^{[30]}$. Leitch et al., in their study on Caucasians isolated coliforms from $5 \%$ of the dental plaque samples ${ }^{[31]}$, while Mobbs et al., showed a $6.6 \%$ prevalence of Enterobacter spices, Pseudomonadaceae, and Acinetobacter spices in 120 healthy individuals. ${ }^{[32]}$

Studies have been done on oral carriage of Enterobacteriaceae in patients with systemic diseases. Back-Brito et al., (2011) in their study on 45 human immunodeficiency virus (HIV) positive and 45 HIV negative patients detected a significantly higher number of Enterobacteriaceae and Pseudomonas in the oral cavities of the HIV positive patients compared to HIV negative patients. [33] Escherichia cloacae were the most frequently isolated species in both groups. Similar studies have been performed on individuals suffering from conditions like HIV-1 ${ }^{[34]}$ and burning mouth syndrome. ${ }^{[35]}$
Enterobacteriaceae usually live in the intestinal tract. Up to $15 \%$ of the population may harbor these organisms in the oral cavity, mostly as transient commensals. Their oral carriage rate may increase in old age, and in conditions leading to reduced salivary flow. [36] Escherichia coli, Enterobacteriaceae and kliebsiella, Proteus and Serratia are mainly in soil, water, plants and animals and are attribute to feco-oral route of infection. They cause diseases such as meningitis, bacillary dysentery, typhoid fever and food poisoning. ${ }^{[10]}$

The oral cavity is a potential portal of entry for organisms into the body, but the commensal oral flora, together with other oral defense mechanisms, plays an important role in protecting the oral cavity from infection by exogenous organisms. These organisms are implicated in chronic inflammatory diseases in the oral cavity. They colonize the mouth by the suppression or modulation of oxygen radical production.

These oxygen radicals induce the production of Reactive Oxygen Species (ROS) in host immune cells which trigger off immune response against the invading microbes. Once suppressed, immune defenses are subverted thereby supporting self-survival and long term carriage of these pathogenic microorganisms in their target host since the effective clearance of colonizing microorganisms is highly dependent on ROS. ${ }^{[37]}$

The normal commensal or oral flora along with the other defense mechanisms, play an important role in protecting the oral cavity from infection by exogenous organisms. In this study, normal oral commensals were found in $10 \%$ of the buccal mucosa isolates, however, the isolation of Escherichia coli and Klebsiella 
species which are predominantly colonic commensals may suggest poor oral hygiene.

The antimicrobial sensitivity pattern is similar to that reported in previous studies. ${ }^{[38,39]}$ The isolates may guide the choice of preoperative antibiotics which hitherto has been based on "best guess".

Greater resistance to Ampicillin and Tetracycline which are Over- The- Counter medications and are frequently used in inadequate doses in our environment was observed. Higher sensitivity to Quinolones (Ciprotab and Sparflotab) presents them as a cheap and available and efficient alternative for use in the management of orofacial infections.

\section{Conclusion}

The isolation of invasive microorganisms in our patients would suggest the need for precautions that would reduce the microflora burden in the perioperative period. The antimicrobial antibiotic sensitivity pattern may also guide the choice of prophylactic antibiotic in our dental clinics. This will obviate the use of best guess antibiotics and therefore reduce the risks of infection in the dental patients.

\section{Acknowledgement}

The authors wish to acknowledge the members of the microbiology laboratory of the University College Hospital, Ibadan for facilitating the Laboratory aspect of this study.

I declare no conflict of interest.

Research was personally financed by the authors. 


\section{References}

1. Malekipour MR, Messripour M, Shirani

F. Buffering Capacity of Saliva in Patients with

Active Dental Caries. Asian J Biochem 2008;3:280-3.

2. $\quad$ Fábián T, Hermann P, Beck A, Fejérdy P, Fábián G. Salivary defense proteins: their network and role in innate and acquired oral immunity. Int J Mol Sci. 2012;13:4295-320.

3. Duerden B, Wide W. Medical and Dental Aspects of Anaerobes. Northwood: Science Reviews; 1995.

4. Umar M, Akafy DE, Abdulkarim IM, Yaya AA, Danasabe YJ. Biochemical characterization and antibiogram pattern of Streptococcus Mutans isolated from dental unit, Sick-Bay, Ahmadu Bello University, Zaria, Nigeria. Int $J$ Bio Biomed Sci. 2015;4:63-6.

5. Batabyal B, Chakraborty S, Biswas S. Role of the oral micro flora in human population: A brief review. Int $J$ Pharm Life Sci 2012;3:2220-7.

6. Allaker R, Hardie J. Oral Infections Microbiology and Microbial. 9th ed. Great Britain: The Bath Press; 1998.

7. Jaber WK. Oral Flora [Internet]. 2013 [cited 2016 Jul 12];Available from: http://www.slideshare.net/wali303/oral-flora25031102 on $10 / 10 / 2016$

8. Hardie J, Bowden G. The normal micro flora of the mouth. In: Skinner F, Carr J, editors. The Normal Microflora of Man. New York: Academic Press; 1974. page 47-84.

9. Baydas B., Uslu H., Yaruz I.,Ceylan I., Dagsugu J.M. Effect of chronic nail biting habit on the carriage of Enterobacteriaceae. $J$ Oral Microbiol and Immunol. 2007;22: 1-4.

10. Reddy S.., Sanjai K., Kumaraswamy J., Papaiah L., Jeevan M. B. Oral Carriage of Enterobacteriaceae among School Children with Chronic Nail - biting Habit. J Oral Maxillofac Pathol. 2013; 17 (2): 163 -168.

11. Kamada N., Seo S., Chen G.Y., Nunez G. Role of gut microbiota in immunity and inflammatory disease. Nature Reviews Immunol 2013, 13: 321 - 335.

12. Mager D, Ximenez-Fyvie L, Haffajee A, Socransky S. Distribution of selected bacterial species on intraoral surfaces. J Clin Periodontol 2003;30:644-54.

13. Avila M, Ojcius D, Yilmaz O. The oral microbiota: living with a permanent guest. DNA Cell Biol 2009 28:405 -411

14. Zarco M, Vess T, Ginsburg G. The oral microbiome in health and disease and the potential impact on personalized dental medicine. Oral Dis 2012;18:109-20.

15. Marsh P.D, Martin M. Oral Microbiology. 3rd ed. London: Chapman and Hall; 1992.

16. Williams R, Browers R, Garrod L, Shooter R. Hospital Infection: Causes and Prevention. London: Lloyd-Luke; 1960.

17. Marsh P.D. Sugar, flouride, $\mathrm{pH}$ and Microbial homeostasis in Dental Plaque. Proc Finn Dent Soc 1991,87 (4): 515 - 525.

18. Pallares R, Liñares J, Vadillo M, Cabellos C, Manresa F, Viladrich PF, et al. Resistance to penicillin and Cephalosporin and Mortality from Severe Pneumococcal Pneumonia in Barcelona, Spain. N Eng J Med 1995;333:47480.

19. Carrol K.C. Normal Human Microbiota. Jawetz, Melnick \& Adelberg's Medical Microbiology. $26^{\text {th }}$ edition. McGraw - Hill Companies, Inc, 2013. Chapter 10. page 165. ISBN 978-0-07-179031-4

20. Larson E. A casual link between handing washing and risk of infection. Examination of evidence. Infect Control 1988;9:28-36.

21. Lewis J, Feckety F. Proteus bacteria. John Hopkins Med J 1969;124:151-6. 
22. Gould F, Magee J, Ingram H. A hospital outbreak of antibiotic-resistant Streptococcus pneumoniae. $J$ Infect 1987;15:77-9.

23. Lidwell O. Aerial dispersal of microorganisms from the human respiratory tract. In: Skinner FA, Carr JG, editors. The normal microbial flora of man. London: Academic Press; 1974. page 135-54.

24. Tesson S, Skjøth C, Šantl-Temkiv T, Löndahl J. Airborne Microalgae: Insights, Opportunities, and Challenges. Appl Env Microbiol 2016;82:1978-91.

25. Noskin G, Stosor V, Cooper I, Peterson L. Recovery of vancomycin resistant enterooccoci on fingertips and environmental surfaces. Infec Control Hosp Epidemiol 1995;16:577-81.

26. Javis W R, Martone W J. Predominant pathogens in hospital infections. J Antimicrob Chemother 1992;29 Suppl.:19-24.

27. Adams B Marie T. Hand carriage of gram negative rods may not be transient. $J$ Hyg 1982;89:33-46.

28. Poeta P., Igrejas G., Goncalves A, Martin E, Araujo C, Carvalho C. et al. Influence of oral hygiene in petients with fixed appliance in the oral carriage of antimicriobial- resistant Esherichia coli and Enterococcus species. Oral Surg Oral Pathol Oral Radiol Endol. 2009; 108: 557 - 564

29. Hable K.A., Washinton J.A. 11, Herriman E.C. Jr. Bacterial and Viral throat flora comparism of findings in children with acute upper respiratofy tract disease and healthy controls in winter. Clin Pediatric 1971: 10: 199-203.

30. Chang J.C.C., Foltz V.D. Obsevations of Pathogenic Coliform bacteria from adult human mouth. J Dent Res 1960: 39: 1120 1127.

31. Leitch J.A., Lang M., Macfarlane T.W., Mackenzie D. The Prevalence and distribution of yeasts and Coliform in dental plaque. $J$ Dent Res 1991; 70: 709 - 712.

32. Mobbs K.J., van Saene H.K., Sunderland D., Davies P.D. Oropharyngeal gram Negative bacillary carriage. A study of 120 healthy individuals. Chest 1999: 115: 1570 - 1575.

33. Back-Brito G.N., El Ackhar V.N., Querido S.M., dos Santos S.S., Jorge A.O., Reis Ade S.et al. Staphylococcus species, Enterobacteriaceae and Pseudomonadeceae Oral isolates from Brazil HIV-positive patients. Correlation with CD4 cell count and Viral load. Arch Oral Biol 2011: 56: 1041 -1046.

34. Schmidth - westhausen A., Schiller R. A., Reichart P.A. Oral Candida and Enterobacteriaceae in HIV-1 infection: Correlation with Clinical Candidiasis and antimycotic therapy. J Oral Pathol Med 1991; 20: 469 - 472.

35. Samaranayake L.P., Lamb A.B., Lamey PJ., Macfarlane T.,W. Oral Carriage of Candida species and Coliforms in Patients with Burning Mouth Sydrome. J Oral Pathol Med 1989; 18: $233-235$.

36. Samaranayake L.P. $3^{\text {rd }}$ ed. Philadelphia: Churchill Livingston.2006. Essential Microbiology for Dentistry. Poor toilet hygiene pp $253-293$.

37. Spooner R, Yilmaz O. The role of reactive Oxygen - Species in microbial persisence and inflammation. Int J Mol Sci 2011;21:334-52.

38. Gaetti - Jardim ti E.C, Marque A.C., Faverani L.P. and Gaetti - Jardim E. Antimicrobial resistance of aerobes and facultative anaerobes isolated frm the oral cavity. J Appl Oral Sci 2010; 548 (6), 551 559.

39. Okoje - Adesomoju V.N., Ifesanya J.U. and Alonge T.O. Antimicrobial Susceptivity Pattern of Oral Microbial Isolates among Pregnant Women in Ibadan South- East Local Government Area, Nigeria. Afr J Biomed Res 2015; 18(3) : 29-35. 
Medical Research Archives, Vol. 5, Issue 5, May 2017

Oral Microbial Isolates from Patients Attending the Dental Clinic, University College Hospital, Ibadan, Nigeria. 